\title{
Serviços de saúde e a violência na gravidez: perspectivas e práticas de profissionais e equipes de saúde em um hospital público no Rio de Janeiro*
}

DANTAS-BERGER, S.M.; GIFFIN, K.M. Healthcare services and violence during pregnancy: perspectives and practices of healthcare professionals and teams in a public hospital in Rio de Janeiro. Interface - Comunic., Saude, Educ., v.15, n.37, p.391-405, abr./jun. 2011.

This article presents preliminary results of semi-structured interviews with 23 healthcare professionals from a public maternity hospital, in the context of an action research project which aimed at promoting the identification of women who suffer violence during pregnancy, and at organizing a routine to support them. The perceptions of gender relations and violence in their personal and professional lives included possible signs of violence which emerge in the consultations and contacts with the patients, and the barriers, possibilities, and necessary conditions for including this question in the hospital routine. We observed that their views were broadened during the interviews and during the subsequent group discussions, in a process of 'constructed visibility' which indicated both the complex social sources of violence and the professional limits and responsibilities that are appropriate to the life situation of their patients and to the working conditions of these professionals.

Keywords: Healthcare professionals. Domestic violence during pregnancy. Gender. Action research.
Este artigo apresenta resultados parciais de entrevistas semiestruturadas realizadas com 23 profissionais de saúde de uma maternidade pública, no contexto de um projeto de pesquisa-ação implantado para promover a identificação e o acolhimento de mulheres que sofrem violência na gravidez. As percepções sobre as relações de gênero e sobre a violência, nas suas vidas particulares e profissionais, incluíram tanto os possíveis sinais de violência apontados no comportamento de pacientes e familiares nas consultas e contatos, quanto as barreiras, possibilidades e condições necessárias para abordarem o assunto na rotina hospitalar. Observamos que suas visões foram ampliadas na entrevista individual e nas discussões coletivas subsequentes, num processo de 'visibilidade construída' que apontou as raízes sociais complexas da violência, bem como os limites e as responsabilidades profissionais apropriadas à situação vivida pelas pacientes e às condições de trabalho desses profissionais.

Palavras-chave: Profissionais de saúde. Violência doméstica na gravidez. Gênero. Pesquisa-ação.
"Elaborado com base no projeto de pesquisa-ação

"Violência doméstica e gravidez de alto risco: qualificando o acolhimento no pré-natal", financiado pelo CNPq e pela Secretaria de Estado de Saúde e Defesa Civil do Rio de Janeiro, mediante projeto de consultoria, treinamento e desenvolvimento do Programa de Assistência Hospitalar à Gestação de Alto Risco - IFF/ PAISMCA/SESDEC/RJ Coordenação: Karen Giffin, 2004-2007 (encerrado).

${ }^{1}$ Programa de PósGraduação, Instituto de Estudos em Saúde Coletiva, Universidade Federal do Rio de Janeiro (IESC/UFRJ)

Praça Jorge Machado Moreira, 100, Cidade Universitária, RJ, Brasil. 21.941-598. sdantasberger@gmail.com ${ }^{2}$ Departamento de Ciências Sociais, Ensp/Fiocruz. 


\section{Apresentação}

A violência na gestação relaciona-se a um padrão muito grave de violência, possivelmente mais frequente do que agravos habitualmente rastreados durante $o$ pré-natal, como o diabetes e a hipertensão arterial (Macfarlane et al., 2002). Isto ratifica a urgência de se incluir este tema, em especial, a violência entre parceiros íntimos (VPI), na atenção às gestantes (Reichenheim, Patrício, Moraes, 2008; Krug et al., 2002).

Este artigo apresenta resultados parciais de um projeto de pesquisa-ação implantado em maternidade pública estadual de referência para gravidez de risco no Rio de Janeiro, entre os anos de 2005 e $2006^{3}$. Nesta pesquisa-ação, foram desenvolvidas estratégias de investigação e intervenção participativas destinadas a sensibilizar e 'formar' profissionais de saúde para a abordagem da violência doméstica na gravidez - problema social complexo, que envolve questões de saúde pública, de direitos humanos e de justiça social.

As atividades desenvolvidas - incluindo entrevistas em profundidade com profissionais de saúde e gestantes atendidas, observações sobre a rotina do serviço, e oficinas e encontros temáticos reflexivo-participativos com a equipe envolvida - colaboraram para uma 'visibilidade coletiva construída' sobre os sintomas e situações associados à VPI e as dificuldades e possibilidades de ação de equipes de saúde frente a tal problema. Analisamos, aqui, entrevistas semiestruturadas realizadas com 23 profissionais da equipe multidisciplinar atuante nesta unidade, que geraram insumos iniciais para encontros mensais e para o planejamento participativo de uma proposta de atuação.

\section{Aspectos teórico-metodológicos}

\section{Políticas neoliberais, 'transição de gênero' e VPI: seria a violência na gravidez um 'sintoma' da 'sociedade de risco'?}

Para abordagem dos elementos construídos sócio-historicamente que contribuem para a ocorrência da VPI, forma mais prevalente de violência vivenciada pelas mulheres, é necessário um enfoque de gênero:

[...] interativo com classe social, raça/etnia, diferenças de geração, capital cultural, etc. e não como uma condição que determina, por si só, diferenciais de vulnerabilidade [...] o gênero é um sistema entre outros que atuam de forma entrelaçada no plano social, com resultados às vezes contraditórios, diferentes para mulheres (e homens) em variadas situações. (Giffin, 2002, p.109)

Deste modo, além de se lançar mão da categoria 'gênero' para se entender como se articulam as diferenças nas relações sociais de sexo e a complexidade do fenômeno da VPI, importaria problematizar tais relações e conflitos na interface entre os aspectos relacionais e estruturais, situando-as em um mundo atravessado por processos de "precariedade do trabalho e vulnerabilidade relacional" (Castel, 1994, p.21).

Tal posição analítica considera que as relações familiares e de gênero ( $e$, também, o trabalho dos profissionais de saúde) estão, agora, situados em uma 'sociedade de risco' (Beck, 2005), consequência da adoção de políticas neoliberais

\author{
${ }^{3} \mathrm{O}$ projeto 'Violência \\ doméstica e gravidez de \\ alto risco: qualificando \\ o acolhimento' (Projeto \\ VDG) foi aprovado \\ pelo Comitê de Ética \\ em Pesquisa da Escola \\ Nacional de Saúde \\ Pública Sérgio Arouca. \\ Entre outros cuidados \\ ético-metodológicos, \\ foram utilizados Termos \\ de Consentimento \\ Livre e Esclarecido com \\ profissionais e gestantes \\ entrevistados, garantido \\ o primeiro acolhimento \\ dos casos de violência \\ detectados e fornecidas \\ informações sobre \\ serviços de referência, \\ complementadas com a \\ distribuição de miniguias \\ de serviços.
}


que precarizam as relações de trabalho e diminuem tanto os rendimentos quanto a estabilidade no trabalho, aumentando a pobreza, ao mesmo tempo em que são restringidos os 'bens de cidadania' que ofereceriam alguma segurança social (Giffin, 2007).

Neste contexto, Castel propõe o conceito de 'desfiliação' para analisar o atual processo de dissociação do vínculo social:

[...] as populações suscetíveis de destacar intervenções sociais estão não somente ameaçadas pela insuficiência de seus recursos materiais como também fragilizadas pela labilidade de seu tecido relacional; não somente em vias de pauperização, mas também em processo de desfiliação, ou seja, em ruptura de vínculo com o social. (Castel, 1994, p.23)

Assim, o desemprego, a informalização e a precarização do trabalho, o empobrecimento e a degradação de serviços públicos se refletem no cotidiano das famílias, inclusive nas relações íntimas entre homens e mulheres. As condições sociais da vida familiar e da reprodução humana são dificultadas, as velhas representações não são sustentadas, as desigualdades de gênero são reformuladas, e homens e mulheres vivem novos conflitos. Desta ótica, a VPI abarca uma questão social complexa, apontando para relações recíprocas entre as condições de saúde e sociais existentes (Giffin, Dantas-Berger, 2007).

Na medida em que estas novas configurações alterem substancialmente a divisão generificada de trabalho anterior, considera-se que estamos passando por uma 'transição de gênero' (Giffin, 2002). Neste processo, ocorre a celebração da 'nova mulher' - que trabalha fora, é independente e 'dona' de seu corpo- junto com o aprofundamento das desigualdades que ela pode viver pela dupla jornada, pelo trabalho precário ou pelos conflitos conjugais daí decorrentes. Uma 'crise da masculinidade', que vem se conformando nos últimos anos com a entrada maciça das mulheres na força de trabalho remunerada e as transformações nas práticas e valores sexuais, coloca em xeque algumas representações e práticas sociais hegemônicas associadas à maternidade, paternidade, sexualidade e divisão social do trabalho. Novos cenários se apresentam para uma análise das relações sociais de sexo, e existem situações nem sempre visibilizadas e consideradas, entre elas a VPI na gravidez.

O lugar ocupado por uma gravidez na vida conjugal e familiar pode ganhar contornos diferenciados, conforme as funções femininas e masculinas sejam reconfiguradas, e as políticas de segurança social e redes de reciprocidade viabilizadas - ou não - dentro deste processo de transição.

As dificuldades crescentes em garantir a sobrevivência familiar por meio de um ganho digno e estável, base da tradicional identidade masculina de provedor, por exemplo, tem estreita relação com a atitude de aceitação ou rejeição masculina perante uma gravidez (Chumpitaz, 2003), e pode estar relacionada com o início da violência doméstica justamente durante a gravidez (Oliveira, Vianna, 1993). Para estes parceiros autores de agressão, uma gravidez que aumente a família, ao invés de afirmar sua potência e virilidade, pode representar uma ameaça, ao ratificar seu fracasso ou 'fragilidade' frente ao que se espera de um pai-parceiro-provedor aos moldes 'ideais'. A ausência de políticas públicas que garantam condições materiais concretas a todas as mulheres e todos os casais para o exercício da maternidade e paternidade segura e responsável, seria outro fator que colaboraria para o agravamento do problema.

Além disto, associados a este quadro de precariedade material, existiriam limites vinculados à permanência de representações sociais de tradição patriarcal, associadas à objetificação da mulher e ao controle da sexualidade feminina, que sustentam a perpetuação da assimetria de poder entre homens e mulheres e a violência contra a mulher. O corpo gravídico pode significar, para alguns homens, o corpo feminino ocupado ou não disponível sexualmente; a suspeita de traição e a negação da paternidade (comuns na vida conjugal de gestantes em situação de violência) seriam outros modos de esta resistência masculina se manifestar (Oliveira, Vianna, 1993).

Estas mudanças denotam o desmonte do tradicional papel masculino de provedor para o qual a maioria dos homens (e mulheres) foi preparada (Giffin, Cavalcanti, 1999). Na análise de Nolasco (1995), a falta de palavras para exprimir sua nova situação pode levar os homens a reagirem com violência, assim como o desemprego, subemprego e ganhos masculinos diminuídos também são 
possíveis fontes de conflito conjugal. Estas dificuldades e insatisfações podem desgastar as relações conjugais e, junto com a recusa feminina ao sexo como 'dever conjugal', virar fontes de violência (Dantas-Berger, Giffin, 2005).

\section{O trabalho e a cidadania 'precarizados': desafios dos profissionais nos processos de trabalho em saúde}

Conforme reforma do Aparelho do Estado de 1995, a Saúde passou a ser considerada como 'serviço', situada no setor terciário. A assimilação dos pressupostos neoliberais no campo da saúde se traduziu em:

[...] mercantilização dos serviços de nível secundário e terciário (cerca de 70\% da oferta estão na iniciativa privada); grande precarização dos vínculos de trabalho no setor público; terceirização de grande parte dos serviços assistenciais e terapêuticos [...]. (Rizzotto, 2006, p.177)

Os processos de privatização e precarização atingiram diretamente os serviços de saúde pública brasileiros e os profissionais de saúde em seu processo de trabalho. Um estudo que investigou a associação entre as condições de trabalho e distúrbios psíquicos menores (DPM) entre médicos da cidade de Salvador demonstrou que:

[...] os médicos foram submetidos às mesmas regras impostas aos demais trabalhadores de qualquer empresa capitalista: instabilidade e precarização do contrato de trabalho, ritmo intenso e jornadas de trabalho prolongadas, redução da remuneração e perda do controle de sua atividade. (Nascimento Sobrinho et al., 2006, p.132)

Neste cenário,

[...] o mercado funciona como princípio organizador do conjunto da vida coletiva, distanciase dos projetos do ser humano emancipado para o exercício de uma humanidade solidária e a construção de projetos sociais alternativos. (Frigotto, Ciavatta, 2003, p.58)

Onde o trabalho é submetido ao 'mercado', interroga-se como resgatar e potencializar valores do cuidado nos atendimentos em saúde, e implantar políticas de 'humanização' (Passos, Benevides, 2006) neste contexto de exigências ao 'cidadão produtivo'.

Este seria, ao que parece, o enorme desafio dos profissionais de saúde quando são convocados a incorporarem a atenção ao tema da violência, fenômeno social crescente e indicador da instalação de uma 'sociedade de risco'. Observa-se que a degradação do trabalho e dos bens da cidadania atingiu tanto sua clientela como sua própria situação como profissionais, resultando: na precariedade dos vínculos empregatícios, na fragilização dos laços sociais e no aumento do enfrentamento pessoal e profissional de situações de conflito e violência.

Portanto, embora se reconheça a dificuldade de se resolverem problemas 'setoriais' sem uma "transformação na esfera da política macroeconômica que condiciona as condições de vida e trabalho de todos" (Giffin, Dantas-Berger, 2007, p. 55), apostamos na necessidade de se enfocar e entender este 'enredo maior' que se impõe a todos, como um caminho possível na direção da construção de outras relações e entendimentos entre os profissionais em seu processo de trabalho, especialmente diante da incorporação da atenção à violência. Isto reforça a necessidade de se abrirem espaços de reflexão sobre estas vivências, tanto para os profissionais de saúde como para as usuárias, reconhecendo-se que ambos são sujeitos capazes de perceberem a natureza social do problema vivido e beneficiarem-se com o compartilhar solidário. 


\section{As entrevistas semiestruturadas}

Nos primeiros três meses do projeto, após levantamento de serviços da rede de violência local, que resultou num miniguia para apoio nos processos de orientação e encaminhamentos subsequentes, 23 profissionais de atenção obstétrica hospitalar e ambulatorial foram entrevistados.

As entrevistas foram realizadas em sala com condições de privacidade, no Centro de Estudos, agendadas conforme disponibilidade de cada profissional, durante seu horário de trabalho e conforme acordado com suas chefias. Duraram, em média, uma hora e dez minutos, foram gravadas, transcritas e codificadas. Apenas um profissional não autorizou sua gravação.

O roteiro, com 34 questões, abordou percepções e significados dos profissionais associados à violência, incluindo temas como gênero, violência doméstica e sexual e gravidez de alto-risco, relacionados à suas experiências pessoais e profissionais, de modo a dar visibilidade a processos institucionais, subjetivos e intersubjetivos compreendidos em tais vivências.

\section{O processo de pesquisa-ação e a 'visibilidade coletiva construída'}

Considerando-se a característica intersubjetiva do trabalho em saúde, lançamos mão da pesquisaação enquanto metodologia de pesquisa qualitativa 'aplicada' à produção do conhecimento e do cuidado em saúde, considerando a mesma:

[...] um tipo de pesquisa social com base empírica que é concebida e realizada em estreita associação com uma ação ou com a resolução de um problema coletivo e no qual os pesquisadores e os participantes representativos da situação ou do problema estão envolvidos de modo cooperativo ou participativo. (Thiollent,1986, p.14)

Como nos apontam Silvério e Patrício (2007, p.242), a metodologia de pesquisa qualitativa já viabiliza um "encontro dialógico-reflexivo". No nosso caso, as entrevistas individuais foram estratégias iniciais de aprofundamento na tomada de consciência da realidade em que os profissionais se encontravam, desnudando e sistematizando diferentes olhares "em busca da reconstrução de uma consciência coletiva" (p.245).

O processo de conscientização individual sobre a gravidade do problema e a maior 'visibilização' dos sinais de violência nos comportamentos das mulheres e familiares, via entrevistas, não pareceu suficiente para que os profissionais se sentissem preparados para incorporar a abordagem do tema na rotina institucional. Questões sobre 'como' atuar em equipe interdisciplinar também surgiram, e orientaram o seguimento das ações do projeto.

O momento inaugural da 'coletivização' do processo deu-se na devolução dos resultados preliminares das entrevistas, em um seminário de quatro horas de duração realizado no Centro de Estudos do próprio serviço. Cada profissional entrevistado recebeu um 'carinhoso' convite escrito individualizado, sendo os demais integrantes da equipe mobilizados em convite geral divulgado pela chefia e em mural de avisos do hospital.

Neste evento, ao se virem representados nas falas e análises apresentadas, e reconhecidos nos seus saberes, puderam sentir-se, de fato, ouvidos e acolhidos, e uma positiva aliança foi estabelecida. Esta "escuta comprometida" (Dejours, 1999, p.10) foi primordial para viabilizar qualquer intervenção posterior. Ao mesmo tempo em que as diferenças foram discutidas, houve um "movimento dialético participativo que fez emergir também a unidade na Equipe de Saúde que até então não havia se expressado" (Silvério e Patrício, 2007, p.243). Novos estudos e ações surgiram destas discussões entre os 'sujeitos-atores' da pesquisa, que caminharam para um 'agir coletivo'. 


\section{Alguns resultados}

\section{Breve perfil dos profissionais entrevistados}

Os 23 entrevistados incluíram 19 mulheres e quatro homens, sendo: oito obstetras, três pediatras, duas enfermeiras, quatro auxiliares de enfermagem, uma técnica de enfermagem, três assistentes sociais e duas psicólogas. A idade dos participantes variou entre 31 e sessenta anos. O grupo de profissionais da maternidade tinha tempo de serviço no hospital entre dois e 26 anos; os do ambulatório de pré-natal, entre dez e 28 anos. A maior parte estava casada ou em união consensual, e apenas seis não possuíam filhos.

\section{Percepções sobre relações de gênero 4}

Perguntamos como viam as relações entre homens e mulheres atualmente, e sobre possíveis mudanças.

Houve algum consenso sobre as mudanças positivas que percebiam para mulheres, no sentido de terem mais estudo e oportunidades de trabalho fora de casa, em especial nas classes mais favorecidas. Alguns ressaltaram e valorizaram mais estes ganhos associando-os à conquista da 'independência feminina':

"Mudanças sempre ocorrem, não é? Hoje a mulher é mais participativa, às vezes é até o chefe da família, não é mais o homem. Ela tem profissão, conseguiu estudar, conseguiu se manter, não é? Então melhorou bastante [...]". ( Ent 2, F)

Outros reconheceram que as mesmas, além dos tradicionais afazeres domésticos e cuidados afetivos com os filhos, passaram a ter, também, mais responsabilidades no orçamento doméstico e a ocuparem a função de provedora (econômica) do lar. Por vezes, tal situação resultaria em sobrecarga para a mulher, que passaria a chefiar sozinha sua casa e a viver processos de 'desestruturação' resultantes, por exemplo, do 'individualismo' pautado pela 'igualdade' entre homens e mulheres, mas que geraria mais desigualdades para a mulher:

"Eu acho que sim, a relação homem-mulher ela modificou bastante de uns anos para cá. Eu acho que nós, mulheres, também pagamos muito caro pela nossa emancipação: porque nós temos que ser profissionais, nós temos que ser mães, dona de casa (risos), e mulher não é? Essa é a grande verdade!". (Ent 9, F)

" [...] as pessoas se igualaram e se individualizaram muito... [...] eu acho que acabou muito a estrutura familiar [...] a mulher assume muito mais papéis atualmente do que o homem [...] em geral na nossa estrutura social o homem se vê como mantenedor até o momento que deseja, ele fica com a mulher até o momento que ele quer, quando não quer ele larga a mulher e ela fica com todo o ônus da situação [...] a igualdade não está acontecendo, está existindo na verdade é um peso maior para a mulher [...]". (Ent 13, M)

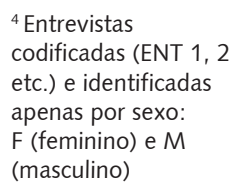


Um dos participantes destaca as mudanças nas relações de gênero e seus efeitos nas relações entre os profissionais:

“[...] Essa mudança não é só dentro de casa, não é só intrafamiliar não. É na relação na rua, é na relação com o colega, com o profissional, da médica com o médico... Antigamente era o seguinte: o colega plantonista [homem] dizia: Não, pode deixar que eu vou resolver - preservava a colega dele . Hoje em dia não!! Assim como ela tem os direitos ela tem as obrigações iguais! [...] A partir do momento que a gente vai competir de igual para igual no mercado, então eu acho que essa mudança houve, muito maior por esse lado...". (Ent 7, M)

Observou-se, também, um maior abandono, pelos parceiros, das grávidas adolescentes e jovens. Por vezes, tal situação foi associada ao que consideraram uma sexualidade livre e barata e à informalidade dos laços:

"A maioria, muitas não têm nem marido, foi um relacionamento assim, um relacionamento que começou a ter, começou a se envolver com o rapaz - que elas pensam que filho prende o homem, não é? Começou com um relacionamento, desse relacionamento vem o filho. E o rapaz ó, foi embora! E fica mais um para criar. Entendeu? Aí ela tem que trabalhar mesmo, porque o cara saiu fora [...]. " (Ent 20, F)

Com relação aos homens, entenderam que alguns procuram dividir mais um pouco as funções de criação dos filhos. Porém, uma condição ressaltada como digna de reflexão foi que, com a maior ocupação e rendimento da mulher no trabalho, alguns homens teriam se 'acomodado', acabando por se responsabilizarem menos ou, mesmo, nem ocuparem suas funções paternas e de colaboração na provisão financeira do lar. Nestes casos, tais parceiros foram nomeados, por alguns participantes, como 'encostados':

"O homem hoje, em relação a tudo isso, eu acho que ele até está deixando de ir muito mais a luta porque ele se encosta muito nesse tipo de mulher, que assume casa para sustentar". (Ent 12, F)

"[...] acho que a mulher tem ido muito à luta e o homem tem se encostado, acomodado". (Ent 16, F)

Relataram, também, que existem determinados parceiros que resistem, não aceitam, ficam mais violentos a partir da ascensão feminina, inclusive quando passam a ganhar menos do que suas companheiras:

"Às vezes, a mulher, quando ela começa a ganhar muito, ela começa até a ser mais vítima da violência do marido - até por insegurança do cara, para colocar ela no lugar dela! Não existe isso?!". (Ent 7, M)

De modo geral, a submissão feminina por dependência financeira e/ou amorosa permaneceria a mesma naquelas uniões onde a mulher, por medo de perder o parceiro, continuaria a aceitar determinadas situações de opressão, submissão, objetificação e violência:

"eu acho que por um lado a gente fala que os homens estão mudando, que as mulheres mudaram muito, mas por outro lado você ainda convive com um grande número de situações, que para mim, não mudaram absolutamente nada.[...] a maioria das mulheres com as quais a gente lida na maternidade, são mulheres que não tem um emprego formal[...], não tem o seu dinheiro. [... ] eu acho a submissão muito grande[...]. A mulher tem um medo absurdo de perder aquele companheiro.[...] Então faz tudo, se submete a qualquer tipo de coisa". (Ent 1, F) 


\section{Concepção da violência contra a mulher}

Questionados sobre o que entendiam por violência contra a mulher e se já atenderam a casos de VPI, a tendência inicial de alguns foi de enfocar a violência física e abuso emocional, naquelas agressões que se revelariam mais explicitamente no corpo ou nas queixas das mulheres, o que se traduzia em relatos de poucos casos de VPI atendidos.

Progressivamente, conforme a entrevista se aprofundava e seus conhecimentos e percepções ganhavam expressão e visibilidade, observou-se que alguns elaboraram uma concepção mais ampliada da violência contra mulheres, ao afirmarem que tal violência não estaria circunscrita aos aspectos físicos e de âmbito conjugal, mas representaria uma soma de fatores estruturais, culturais, institucionais e interpessoais, entre outros.

Deste modo, as modalidades de violência 'psicológica' e 'moral' contra a mulher passaram a ganhar expressão e foram consideradas tão ruins ou, até, mais comuns que a violência física: culpabilizações por coisas que não dão certo na rotina da casa; ameaças constantes de retirada da guarda dos filhos; falta de apoio e/ou abandono da mulher pelo parceiro e/ou familiares na gravidez; restrição da liberdade de ir e vir e cárcere privado, entre outras:

"aqui no ambulatório o que eu percebo da violência, que às vezes acontece é uma gravidez não desejada, principalmente das mais jovens [...] ela acaba ficando sozinha, abandonada pelo parceiro[...]não é uma agressão física, mas é uma violência moral que depois que ela vai perceber". (Ent 14, M)

Por outro lado, consideraram que tanto homens como mulheres são autores de violência psicológica e, portanto, as parceiras não seriam somente 'vítimas' nas situações de conflito conjugal.

Ainda com relação aos tipos de violência vivenciados especialmente pelas mulheres, coube ainda menção ao sexo conjugal como 'obrigação', inclusive durante o período da gravidez. Ainda que destacado como uma violência por alguns profissionais, reconheceu-se que, muitas vezes, tal prática não é assim nomeada ou identificada pela própria mulher:

\footnotetext{
"Mas, engraçado é que as coisas mudaram em alguns aspectos, mas ainda tem muitos resquícios - a vítima de violência sexual, principalmente se for do marido, parece que não chega a ter consciência de que aquilo é violência... Ela aprendeu que ela tinha obrigação de servilo. [...] Quando a mulher chega e diz para você que ela tem relação mas não tem prazer, ela cumpre obrigação, isso é violência não é? " . (Ent 7, M)
}

A discriminação e violência contra a mulher, resultante de fatores estruturais e institucionais, inclui a falta de apoio e proteção social que cercam sua vida sexual e reprodutiva, inclusive no ciclo gravídicopuerperal: mulheres que têm filhos e não têm onde deixar para trabalhar; estão grávidas e não têm serviços; não querem engravidar e não têm ou não conseguem negociar métodos; precisam comer melhor e estão sem licença-maternidade ou sem recursos; que passam dificuldades e são julgadas nos serviços ou são discriminadas pela baixa adesão nas consultas de pré-natal e/ou aos tratamentos e cuidados recomendados.

"[...] Chegar aqui e subir 4 lances de escada, e todo mundo dizer que esta mulher tem que estar feliz e contente!". (Ent 8, F)

“[...] Para quem tem que pegar água para dar banho na criança, tem que passar roupa, fazer comida, e botar mais 3 na escola! É muito diferente da nossa visão de amamentação! [...] Porque amamentar dá uma fome desgraçada, você fica enlouquecida, faz hipoglicemia toda hora, você imagina ela, que não tem nada para comer, [...] eu acho que isso tudo é violência!". (Ent 8, F) 
É importante ressaltar que nem todos os profissionais, no início, expressaram um entendimento amplo e crítico do que seria a violência contra a mulher. As discussões coletivas dos resultados da pesquisa e da prática profissional, no entanto, efetivaram, posteriormente, um processo de coletivização e potencialização desta visão.

\section{Motivos associados aos casos de violência praticada pelo homem contra suas parceiras}

Muitos entrevistados citaram o uso de álcool e drogas como fator associado à ocorrência da violência, alguns justificando o comportamento masculino por isso, enquanto outros situaram tal consumo e/ou abuso apenas como fator desencadeante, destacando também os aspectos estruturais:

\footnotetext{
"Sei lá, eu acho o seguinte, eu acho que tem muito a questão também da bebida. O homem que bebe, que acaba se excedendo e agredindo. Tem também essa questão dessa vida difícil, desse stress, esse desemprego, e, de repente, o homem está vendo que não está sendo suficiente para suprir aquela família. E, também fica nervoso, estressado, seria uma causa também de violência na mulher e até nos filhos também, não é? ". (Ent 3, F)
}

Além da violência doméstica vivida na infância pelo parceiro, as questões culturais associadas ao machismo foram também mencionadas, identificadas nas situações onde a mulher seria vista como objeto pelo parceiro e no 'desejo de dominação' masculina, expresso no ciúme doentio que alguns homens manifestariam com relação à sua parceira.

A associação entre fatores atribuídos às particularidades da relação social de sexo hegemônica e fatores econômicos como o desemprego masculino se refletiria, em alguns casos, na cobrança que certas mulheres fazem sobre o homem, no sentido de que o mesmo ocupe o tradicional lugar de 'provedor', sendo este outro motivo identificado, nas entrevistas, para desencadear brigas e agressões entre o casal:

\footnotetext{
“Você vai para casa, às vezes você não trabalha, depende dele, então você fica naquela necessidade de estar cobrando as coisas do pai, ele fala que não tem. [...] Aí, quer dizer, eu acho que é mais complicado para mãe do que para o homem. O homem vai pra rua, ela fica, sabe? Também não vou dizer que ele não está nem aí. Até está, ele sente, porque ele tem que dar o leite para o filho". (Ent 20, F)
}

\section{A violência na vida dos entrevistados}

Preocupações relativas à violência urbana foram comuns, incluindo seus próprios medos com relação a assaltos, bala perdida, segurança dos filhos. Uma participante trouxe um retrato trágico: dos seus quatro filhos, dois eram falecidos - um por bala perdida e outro por acidente de trânsito, e outro estava desaparecido.

Com relação à violência conjugal na vida de parentes próximos, foram citadas situações envolvendo pais, sogros, filhos e irmãos dos profissionais. Outra situação bastante mobilizadora e trágica foi relatada sob forte emoção:

\footnotetext{
“Eu tive um exemplo muito grande na minha família... Minha irmã não estava grávida, mas o que o companheiro dela fez com ela, na frente de uma criança de 4 anos... [voz embargada] [...] Minha irmã se separou dele porque descobriu que estava envolvido com drogas, e ele fez de tudo para voltar... Ela saiu da casa que era dela. Um dia ele chegou lá no quartinho que ela tinha comprado - só tinha uma porta - de noite...[e, na manhã seguinte ] quando arrombaram a porta, minha irmã estava morta, ele deitado do lado dela!!! [...] usada [estuprada] [...] Ela não queria e ele forçou... Ela tinha as marcas aqui [mostra o pescoço]". (Ent 4, F).
} 
$\mathrm{Na}$ vida conjugal com parceiros atuais e passados, houve relatos de atritos e agressões vividos tanto por profissionais do sexo feminino como do masculino. As situações de VPI na vida pessoal relacionavam-se à relação sexual forçada no casamento, ameaças e estresse psicológico nos momentos de separação de casal e definição de guarda de filhos.

\section{Como a violência afetaria os serviços de saúde}

Foram identificadas formas como a violência urbana interferiria na rotina do serviço de saúde: no ambulatório, gestantes moradoras em áreas de risco para o tráfico de drogas faltariam às consultas agendadas por temerem complicações na sua saída ou retorno para casa; na internação, a mulher precipitaria sua saída ('alta à revelia'); na emergência, casos de mulheres baleadas ou esfaqueadas, inclusive na barriga:

"[...] tive só uma gestante que, na época, [...] ela não foi violentada assim, mas comentou [justificando sua falta à consulta] que morava num morro e [...] que familiares estariam sendo relacionados ao tráfico, então tinha que sair dali, que fugir para outro lugar, sendo ameaçada". (Ent 2, F)

$\mathrm{Na}$ atenção que prestavam, alguns seriam mais cautelosos quando suspeitassem ou fossem informados de que a mulher tivesse ligação com traficantes. Por outro lado, os profissionais se mostraram preocupados com a possibilidade de eles mesmos saírem mais tarde do hospital, localizado em zona insegura, onde é comum serem ouvidos tiroteios noturnos.

\section{Violência na gravidez:}

\section{como as mulheres expressariam e os profissionais perceberiam seus sinais?}

Interrogados se as mulheres declaravam a violência nos atendimentos e se eles costumavam 'suspeitar ' de casos de violência entre a população atendida, a maioria respondeu que a mulher não declara direta e espontaneamente tal violência, quer seja por vergonha, medo de represália dos parceiros ou de serem julgadas por terceiros; por banalizarem as agressões cotidianas vividas em suas relações conjugais ou familiares; por entenderem que suas consultas se restringiriam aos exames e sintomas clínicos; ou por não sentirem espaço ou confiança suficientes para falarem sobre tais problemas no atendimento em saúde, entre outros motivos.

Muitos informaram que, somente 'às vezes', suspeitavam da violência doméstica nos atendimentos e, com maior frequência, dos casos de violência psicológica. Conforme a entrevista foi se desenrolando e as experiências dos profissionais foram revivificadas em suas reflexões e relatos da prática profissional, a possibilidade da violência na rotina dos atendimentos foi se tornando mais visível (ainda que não identificada como tal no início das entrevistas ou nos atendimentos que prestaram).

Algumas condições diferenciadas na interação com a gestante, bem como relatos indiretos de agressões e conflitos não explicitados pelas gestantes, foram sendo demarcados como possíveis sinais de alerta.

A 'bolsa rota' precocemente foi questionada: "por que tantos casos no serviço"? (Ent 6, F). A frequência irregular ao pré-natal ou, mesmo, o abandono e a ausência do mesmo, a instabilidade da pressão, as queixas difusas, as dores na barriga, seriam alguns outros sinais que poderiam apontar para dificuldades vividas pelas gestantes nas relações de intimidade.

Também as perguntas ou preocupação excessiva sobre a frequência ou, mesmo, sobre a restrição ao sexo na gravidez - traduzidas, por vezes, na solicitação ao médico para dar por escrito tais recomendações - poderiam demonstrar a fragilidade da mulher na negociação do sexo quando não o deseja, indicador importante da qualidade da relação: 
“Às vezes uma que vem com o marido, quando está mais assim para o final [da gravidez], pergunta se pode estar tendo relação ainda. [...] Quando o marido está, você percebe que ela já falou com ele mas que ele não aceitou, então ela traz até para que eu confirme - que um determinado período ela pode se sentir desconfortável...". (Ent 2, F)

Em outra indagação reflexiva, um participante pergunta - 'E aquelas que estão sempre sós nos atendimentos?' (Ent 5, F) - passando a refletir sobre a possibilidade da falta de apoio familiar e o abandono pelo parceiro serem fatores relacionados às situações de violência.

Questionaram, ainda, o que de fato a gestante estaria apontando quando insiste na realização de ultrassonografia, mesmo sem haver qualquer indicação clínica "evidente" para tal?

"O marido foi embora, deixou ela grávida... O marido era "ruinzinho" para ela - puxava cabelo, dava pontapé. Aí ela veio fazer tratamento, pré-natal, ficou com vergonha de conversar com a médica que atendeu. Aí a médica perguntou por que ela queria pedir uma ultrassom? Aí ela falava: - Não... eu só queria saber do neném, e tal, mudava de assunto e não dizia o que era...". (Ent 21, F)

Com relação às puérperas, citaram alguns comportamentos na relação com o recém-nascido, como a pouca participação na rotina (banho dos bebês etc.), que poderiam estar associados a dificuldades na aceitação de uma gravidez não desejada. A ausência do pai do bebê nas visitas ou os conflitos familiares que resultariam no típico "stress pós-visita" poderiam sugerir dificuldades na convivência com os mesmos.

\section{Barreiras e sugestões para se conversar com a gestante sobre a relação com o parceiro e situações de violência}

Indagou-se se achavam que poderiam perguntar sobre a relação com o parceiro e situações de agressão e violência. A maioria disse que sim, mas com algumas condições: desde que tivesse condições de privacidade porque é uma pergunta delicada; se tomasse cuidado para não chocar a paciente (saber fazer a abordagem); se não fosse só pelo interesse estatístico, só para notificação; se estivesse claro, para os profissionais, 'por que e para que' perguntar; se soubesse o que fazer nos casos positivos, ou como dar os devidos encaminhamentos, sendo garantido algum retorno ou seguimento para a mulher.

Entre profissionais que afirmaram ser positivo incluir a abordagem da relação com o parceiro e a história pregressa de violência no atendimento, tanto a qualidade da relação profissional de saúdeusuária como a qualificação da equipe foram apontadas como condições para o êxito, havendo ainda preocupação de alguns quanto ao registro de tal situação em prontuário e, também, quanto ao estabelecimento de rotinas rígidas:

"Acho que depende do vínculo que você tem com o paciente, depende do momento, depende de onde você está atendendo essa paciente, eu não sou a favor de rotinas, daquele protocolo que você tem lá aquela lista de perguntas que tem que ser feitas, isso eu acho complicado [...] acho que a gente tem que ter muito cuidado com a intimidade do paciente, [...] com o que você coloca no prontuário[...] é uma coisa complexa, não é só se deve perguntar ou não deve perguntar, depende; depende de quem vai perguntar, com que objetivo, fazendo parte do quê que vai ter essa pergunta". (Ent 19, F)

Entre as barreiras citadas para se atuar nos casos de violência, três grupos de respostas dominaram. Em primeiro lugar, os limites da formação profissional baseada em modelo biomédico, que privilegia a prática clínica com rotinas mecanizadas, com pouca interação médico-paciente: 
“[...]. É uma coisa que até a gente pode começar a pensar mais... Porque a gente sempre acha que pode ser uma coisa infecciosa - a gente pede urina, a gente examina, a gente vê se tem corrimento ou não [...] e acaba que esquece de perguntar essas coisas importantes". (Ent 9, F)

O segundo grupo de respostas demonstrou ser a violência um tema 'sensível e sensibilizador' (Schraiber, D'Oliveira, Couto, 2009) que mobiliza vivências pessoais dos profissionais, bem como mitos e preconceitos relacionados ao gênero:

“[...] quando vim para cá eu não tinha preparo para isso [...] a vontade que eu tinha era de partir, dar porrada também no agressor. Eu não conseguia ver aquele agressor como alguém que também precisava de atendimento...". (Ent 23, F)

Um último grupo de respostas sinalizou a necessidade de retaguarda institucional: recursos materiais, técnicos e humanos; espaço físico com privacidade para aconselhamentos; uma rotina interdisciplinar para seguimento dos casos; e mais tempo de consulta para incluir a abordagem da violência.

Sugestões sobre 'como fazer' se dividiram: uns demandariam um protocolo ou rotina institucional; alguns viam que tal procedimento deveria fazer parte de qualquer atendimento; outras só quando se suspeitasse da violência. Alguns apontavam momentos, espaços de atendimento mais propícios e profissionais mais qualificados (na anamnese obstétrica, na rotina de pré-natal, pelo obstetra na $1^{\text {a }}$ consulta ou depois que ganhasse a confiança da paciente, ou pela equipe multiprofissional, desde que se definisse o papel de cada um entre detectar, acolher e encaminhar), sendo ainda mencionada a importância do esclarecimento informado das mulheres sobre tal procedimento.

Um dos participantes do ambulatório não concordou com a possibilidade de incluir o tema da violência nos atendimentos, e outros dois, da maternidade, fizeram restrições: que tal procedimento nunca ocorresse no momento de internação para o parto; e que nunca se deveria perguntar diretamente sobre o evento:

“[...] Até perguntar como é sua vida em casa, isso é cabível, Mas, [...] você perguntar: 'seu marido te agride?' Acho que é a melhor maneira para cortar toda e qualquer coisa... Você não pode ser direto a esse ponto. [...] ela vai se retrair, aí que ela não vai contar mesmo". (Ent 7, M)

\section{Discussão e conclusões}

É, portanto, através da ótica qualitativa que podemos efetivamente captar, compreender e construir estratégias que possam transformar os complexos, sutis e nem sempre explícitos conflitos, dilemas, impasses e contradições que perpassam a assistência à saúde, particularmente no campo reprodutivo. Esta abordagem nos capacita a propor mudanças que efetivamente considerem e incorporem as necessidades e expectativas dos/as pacientes e dos/ as profissionais de saúde [...]. (Simões-Barbosa, 2006, p.20)

O objetivo desta pesquisa-ação foi o de encontrar caminhos para o acolhimento das mulheres/ gestantes em situação de violência, considerando a realidade apontada pelos profissionais. Concluise que não há como se alcançar tal tarefa sem que se promovam reflexões coletivas, no dia a dia dos serviços, sobre o processo de transição de gênero na sociedade de risco. Constata-se que tal proposta tem potencialmente a força de dar mais 'visibilidade' a fenômenos e processos sociais complexos, fortalecendo os sujeitos do serviço de saúde tanto para o reconhecimento das condições sociais, de direitos humanos e de justiça social envolvidos, como para avançarem na identificação e tratamento dos agravos físicos, psíquicos e sexuais decorrentes da violência entre parceiros íntimos. 
As situações associadas à precariedade do trabalho e vulnerabilidade relacional na vida das gestantes e puérperas atendidas na unidade materno-infantil pesquisada foram determinantes no processo de trabalho cotidiano dos profissionais de saúde entrevistados e na percepção do problema da violência na vida das mulheres, assim como na definição dos atendimentos considerados mais complexos.

Embora citassem os riscos materno e fetal apresentados pela maior parte da clientela, não foram os problemas 'clínicos' que mais inquietavam, mas sim as dificuldades relacionadas ao sucateamento do serviço público e seus efeitos na oferta de vagas, insumos e recursos humanos, na gestão da rede e apoio externo ao serviço.

Porém, conforme os profissionais apresentavam suas percepções das dificuldades presentes nas relações íntimas e na vida comunitária das mulheres atendidas, surgiu a questão da formação em saúde baseada no modelo biomédico, que reproduz uma profissionalização mecanicista, focada na doença, e não no 'sujeito'.

Como disse um dos entrevistados, limitar sua consulta ao 'examinar' e 'tratar' de doenças detectadas seria insuficiente, frente ao reconhecimento de que 'conversar' sobre 'coisas', como a relação com o parceiro, é fundamental no rastreamento da violência - e fundamental, apontamos, para que o princípio da integralidade seja praticado no SUS.

Resgatar e aprofundar a visão e a experiência dos profissionais de saúde via as entrevistas individuais iniciou um processo de formação diferenciado, que partiu dos conhecimentos apresentados pelos mesmos para iluminar um quadro epidemiológico e de sintomatologia associada, aplicado àquela população e serviço. Reconhecidos e fortalecidos em seus saberes práticos, os profissionais avançaram em novos questionamentos que os ajudaram: a identificar situações associadas à violência, a desconfiar da frequência com que lidavam com as mesmas e a assumir tanto limites pessoais (medos, preconceitos, conhecimentos) como responsabilidades profissionais (para além de notificar o 'agravo', saber como e quando perguntar sobre a violência).

No processo de devolução dos resultados da pesquisa, sistematizados pelas pesquisadoras e discutidos em processo grupal, tais saberes e práticas foram coletivizados, possibilitando a troca de experiências entre os mais antigos e os mais novos, entre serviço e academia, a partir de uma realidade comum partilhada que abriu um caminho para a construção de um processo participativo de reflexão e educação no cotidiano do serviço de saúde.

Além de tais reflexões promoverem um acolhimento mais justo à população, também poderiam colaborar na construção ou resgate de uma 'sociabilidade solidária' (Luz, 2008) entre os próprios profissionais, e de uma resistência à cultura capitalista e seus valores neoliberais, inclusive no trabalho em saúde.

\section{Colaboradores}

Sônia Dantas Berger participou da elaboração, coordenação e implementação de todas as etapas do Projeto VDG, elaborou a primeira versão do texto e participou de todas as etapas posteriores. Karen Giffin coordenou o projeto VDG e participou da revisão e da elaboração da versão final do manuscrito.

\section{Agradecimentos}

As autoras agradecem, especialmente, aos profissionais da unidade de saúde, pela participação na pesquisa-ação; à Janaína Marques de Aguiar, pelo apoio na coleta de dados e implementação do projeto, e à Dra Tizuko Shiraiwa, pela assessoria técnica na seleção da unidade de saúde e no acompanhamento global do projeto. 


\section{Referências}

BECK, U. Risk society: towards a new modernity. London: Thousand Oaks, 2005.

CASTEL, R. Da indigência à exclusão, a desfiliação: precariedade do trabalho e vulnerabilidade relacional. In: LANCETTI, A. (Org.). Saúde Loucura, n.4 (Grupos e coletivos). São Paulo: Hucitec, 1994. p.21-48.

CHUMPITAZ, V. Percepções femininas sobre a participação do parceiro nas decisões reprodutivas e no aborto induzido. 2003. Dissertação (Mestrado) - Escola Nacional de Saúde Pública, Fundação Oswaldo Cruz, Rio de Janeiro. 2003.

DANTAS BERGER, S.M.; GIFFIN, K. A violência nas relações de conjugalidade: invisibilidade e banalização da violência sexual? Cad. Saude Publica, v.21, n.2, p.417-25, 2005.

DEJOURS, C. Conferências brasileiras: identidade, reconhecimento e transgressão no trabalho. São Paulo: Fundap: EAESP/FGV, 1999.

FRIGOTTO, G.; CIAVATTA, M. Educar o trabalhador cidadão produtivo ou o ser humano emancipado? Trab. Educ. Saude, v.1, n.1, p.45-60, 2003.

GIFFIN, K. Financeirização do Estado, erosão da democracia e empobrecimento da cidadania: tendências globais? Cienc. Saude Colet., v.12, n.6, p.1491-504, 2007

Pobreza, desigualdade e eqüidade em saúde: considerações a partir de uma perspectiva de gênero transversal. Cad. Saude Publica, v.18, supl., p.S103-S112, 2002.

GIFFIN, K.; CAVALCANTI, C. Homens e reprodução. Rev. Estud. Fem., v.7, n.1/2, p.53-71, 1999.

GIFFIN, K.; DANTAS BERGER, S.M. Violência de gênero e sociedade de risco: uma abordagem relacional. In: TAQUETTE, S. (Org.). Violência contra a mulher adolescente-jovem. Rio de Janeiro: Eduerj, 2007. p.55-60.

KRUG, E.G. et al. (Eds.). World report on violence and health. Geneva: World Health Organization, 2002.

LUZ, M. Conferência de abertura. Bol. Integralidade Saúde, 10 set. 2008. Disponível em: <http://www.lappis. org.br/cgi/cgilua.exe/sys/start.htm?infoid=1031\&sid=20>. Acesso em: 13 abr. 2010.

MCFARLANE, J. et al. Abuse during pregnancy and femicide: urgent implications for women's health.

Obstet. Gynecol., v.100, n.1, p.27-36, 2002.

NASCIMENTO SOBRINHO, C.L. et al. Condições de trabalho e saúde mental dos médicos de Salvador, Bahia, Brasil. Cad. Saude Publica, v.22, n.1, p.131-40, 2006.

NOLASCO, S. A desconstrução do masculino. Rio de Janeiro: Rocco, 1995.

OLIVEIRA, E.M.; VIANNA, L.A.C. Violência conjugal na gravidez. Rev. Estud. Fem., v.1, n.1, p.162-5, 1993.

PASSOS, E.H.; BENEVIDES, R.D. Humanização. In: PEREIRA, I.B.; LIMA, J.B.F. (Orgs.). Dicionário da educação profissional. Rio de Janeiro: EPSJV/Fiocruz, 2006. p.153-8.

REICHENHEIM, M.E.; PATRICIO, T.F; MORAES, C.L. Detection intimate partner violence during pregnancy: awareness-raising indicators for use by primary healthcare professionals. Public Health, v.122, n.7, p.716-24, 2008.

RIZZOTTO, M.L.F. Neoliberalismo em saúde. In: PEREIRA, I.B.; LIMA, J.C.F. (Orgs.). Dicionário da educação profissional. Rio de Janeiro: EPSJV/Fiocruz, 2006. p.173-7.

SCHRAIBER,L.B.; D'OLIVEIRA, A.F.P.L.; COUTO, M.T. Violência e saúde: contribuições teóricas, metodológicas e éticas de estudos da violência contra a mulher. Cad. Saude Publica, v.25, suppl.2, p.205-16, 2009.

SILVÉRIO M.R.; PATRICIO Z.M. O processo qualitativo de pesquisa mediando a transformação da realidade: uma contribuição para o trabalho de equipe em educação em saúde. Cienc. Saude Colet., v.12, n.1, p.239-46, 2007.

SIMÕES BARBOSA, R.H. Avaliação qualitativa de um programa de assistência à saúde de gestantes HIV+. In: BOSI, M.L.M.; MERCADO, F.J. (Orgs.). Avaliação qualitativa de programas de saúde: enfoques emergentes. Petrópolis: Vozes, 2006. p.313-46.

THIOLLENT, M. Metodologia da pesquisa-ação. São Paulo: Cortez/Autores Associados, 1986. 
BERGER, S.M.D; GIFFIN, K.M. Servicios de salud y violencia durante el embarazo:

perspectivas y prácticas de profesionales y equipos de salud en un hospital público en Rio de Janeiro. Interface - Comunic., Saude, Educ., v.15, n.37, p.391-405, abr./jun. 2011.

Este artículo presenta los resultados parciales de entrevistas semi-estructuradas realizadas con 23 profesionales de salud de una maternidad pública en el contexto de un proyecto de investigación-acción implantado para promover la identificación y el cuidado de la salud de mujeres que sufren de violencia durante el embarazo. Las percepciones sobre las relaciones de género y la violencia, en sus vidas particulares y profesionales, incluyeron las posibles marcas de violencia señalados en el comportamiento de pacientes y de sus familiares durante las consultas, así como las barreras, posibilidades y condiciones necesarias para afrontar el asunto en la rutina del hospital. Observamos que sus visiones fueron ampliadas a través de la entrevista individual y en las discusiones colectivas subsecuentes en un proceso de "visibilidad construida" que a señala las raíces sociales de la violencia y responsabilidades profesionales apropiadas a la situación de las pacientes y las condiciones de trabajo de estos profesionales.

Palabras clave: Profesionales de salud. Violencia doméstica en el embarazo. Género. Investigación-acción. 
